\title{
PENGARUH TEKNOLOGI INFORMASI DAN KOMUNIKASI TERHADAP TINGKAT KEMISKINAN DI INDONESIA TAHUN 2012-2017
}

\author{
(The Influence of Information and Communication Technology on Poverty Levels in \\ Indonesia, 2012-2017)
}

\author{
Khoirunnisa ${ }^{1}$, Winih Budiarti ${ }^{2}$ \\ Politeknik Statistika STIS ${ }^{1}$ \\ Politeknik Statistika STIS ${ }^{2}$ \\ Jalan Otto Iskandardinata No. 64C, Jakarta \\ E-mail: 15.8693@stis.ac.id
}

\begin{abstract}
ABSTRAK
Angka kemiskinan Indonesia terus menurun dari tahun ke tahun. Akan tetapi, penurunan angka kemiskinan ini masih belum memenuhi target yang ditetapkan pemerintah seperti MDGs dan RPJMN 20092014. Perlu adanya strategi baru oleh pemerintah untuk mengejar target pengentasan kemiskinan, salah satunya melalui teknologi informasi dan komunikasi (TIK). TIK dianggap mampu mempercepat pengentasan kemiskinan di banyak negara. Perkembangan TIK dapat dilihat melalui Indeks Pembangunan Teknologi Informasi dan Komunikasi (IP-TIK). IP- TIK Indonesia mengalami peningkatan tiap tahun. Selain TIK, diperlukan infrastruktur lain yang menunjang keberadaan TIK, seperti infrastruktur jalan dan listrik serta adanya pemerataan pembangunan yang dapat dilihat melalui PDRB per kapita. Adanya otonomi daerah menyebabkan adanya ketidakmerataan pembangunan antar provinsi. Penelitian ini bertujuan untuk mengetahui pengaruh IP-TIK serta variabel lainnya terhadap tingkat kemiskinan pada masing-masing provinsi di Indonesia dengan menggunakan analisis data panel tidak seimbang (unbalanced data panel). Hasil penelitian menunjukkan bahwa model regresi yang terpilih adalah Random Effect Model (REM). Hasil REM menunjukkan bahwa IP-TIK, PDRB per kapita, infrastruktur jalan, dan infrastruktur listrik berhubungan negatif dan signifikan secara statistik terhadap tingkat kemiskinan di Indonesia.
\end{abstract}

Kata kunci: IP-TIK, Infrastruktur, Kemiskinan, Data panel, Indonesia

\section{ABSTRACT}

Indonesia's poverty rate slowly decrease along with the time. However, the decline in poverty still unreach the targets set by the government such as MDGS and RPJMN 2009-2014. The government needs a new strategy to pursue the goals of poverty alleviation, one of which is through Information and Communication Technology (ICT). ICTs are considered capable of acceleration poverty reduction in many countries. The development of ICT can be seen from ICT Development Index (IDI). Indonesian IDI has increased every year. In addition to ICT, other infrastructure that support the existence of ICT are needed, such as road and electricity as well as the distribution of development that can be seen through GDRP per capita. The presence of regional autonomy has led to the development of inequality between provinces. Therefore, to study the effect of ICT Development Index and other variables toward poverty rate in each provinces of Indonesia using unbalaned data panel analysis. The result showed that the model regression is Random Effect Model. Based on the REM regression model shows that ICT Development index, GDRP per capita, road, and eletricty statistically significant negatif influences the poverty rate in Indonesia.

Keywords: ICT Development Index, Infrastructure, Poverty, Data panel, Indonesia 


\section{PENDAHULUAN}

Salah satu tujuan utama program Millenium Development Goals dan Sustainable Development Goals adalah pengentasan kemiskinan di seluruh dunia, tidak terkecuali Indonesia. Angka kemiskinan Indonesia menunjukkan perkembangan yang positif dimana terjadi penurunan dari tahun ke tahun. Sejak mencapai puncak akibat krisis moneter di tahun 1998, tingkat kemiskinan Indonesia terus mengalami penurunan. Keberhasilan penurunan kemiskinan ini tidak terlepas dari adanya pembangunan dan berbagai program pengentasan kemiskinan yang dilakukan pemerintah. Pembangunan memiliki tiga tujuan yaitu, peningkatan ketersediaan dan perluasan distribusi kebutuhan pokok, peningkatan standar hidup, dan perluasan pilihan ekonomi dan sosial (Todaro, 2011).

Tabel 1. Target dan Realisasi Angka Kemiskinan Indonesia.

\begin{tabular}{ccc}
\hline Program & Target & Realisasi \\
\hline MDGs & $7,5 \%(2015)$ & $11,22 \%(2015)$ \\
RPJMN 2009-2014 & $8-10 \%(2014)$ & $11,25 \%(2014)$ \\
\hline
\end{tabular}

Sumber : Badan Pusat Statistik

Namun meskipun angka kemiskinan mengalami penurunan, tetapi laju penurunan kemiskinan Indonesia sangat lambat yang menyebabkan target pengentasan kemiskinan belum tercapai. Menurut MDGs dan RPJMN 2009-2014, target pengentasan kemiskinan Indonesia adalah dibawah 10\%. Akan tetapi, realisasi angka kemiskinan Indonesia tahun 2014 dan 2015 belum mampu mencapai target yang telah direncanakan.

Kemiskinan tidak hanya merupakan permasalahan dari segi ekonomi saja tetapi merupakan permasalahan yang kompleks, yaitu dari segi budaya, sosial, psikologi, dan geografi. Salah satu penyebab kemiskinan adalah karena kurangnya akses informasi pada orang miskin (Widiastuti, 2010). Informasi memungkinkan seseorang untuk mengembangkan ide, mendapatkan peluangpeluang baru, dan mendapat pembelajaran dari orang lain. Pemerataan pembangunan hanya efektif jika dilakukan seiring dengan pemerataan informasi dan komunikasi (Dahlan dalam Widiastuti, 2010). Menurut Subhan dan Mujer, program bantuan pemerintah bagi orang miskin, seperti bantuan modal dan kebutuhan pokok seringkali tidak tepat sasaran karena keterbatasan informasi (Yusup, Kuswarno, dan Kurniasih, 2017). Orang miskin memiliki keterbatasan untuk mendapatkan informasi secara cepat terkait hal-hal yang memungkinkan untuk meningkatkan kualitas hidup. Mereka cenderung terlambat mengetahui informasi ketersediaan peluang usaha yang sebenarnya bisa dilakukan jika mendapatkan informasi lebih cepat.

Pemerataan informasi dan komunikasi diperlukan untuk mempercepat pengentasan kemiskinan di berbagai bidang, seperti di bidang ekonomi, politik, dan kesejahteraan rakyat. Pemerataan informasi dan komunikasi saat ini paling efektif dilakukan dengan teknologi. Teknologi informasi dan komunikasi (TIK) ini memungkinkan terjadinya pertukaran informasi secara cepat dan efisien.

Potensi teknologi informasi dan komunikasi sebagai alat yang efektif untuk mengurangi kemiskinan telah dibuktikan di beberapa negara berkembang seperti Peru, Cina, Kepulauan Solomon, Zimbabwe, dan India (Bappenas dan UNDP, 2008). TIK memberikan peluang usaha dan penghasilan serta meningkatkan keefektifan pelayanan jasa masyarakat sehingga meningkatkan kualitas kehidupan (Widiyastuti, 2015). 


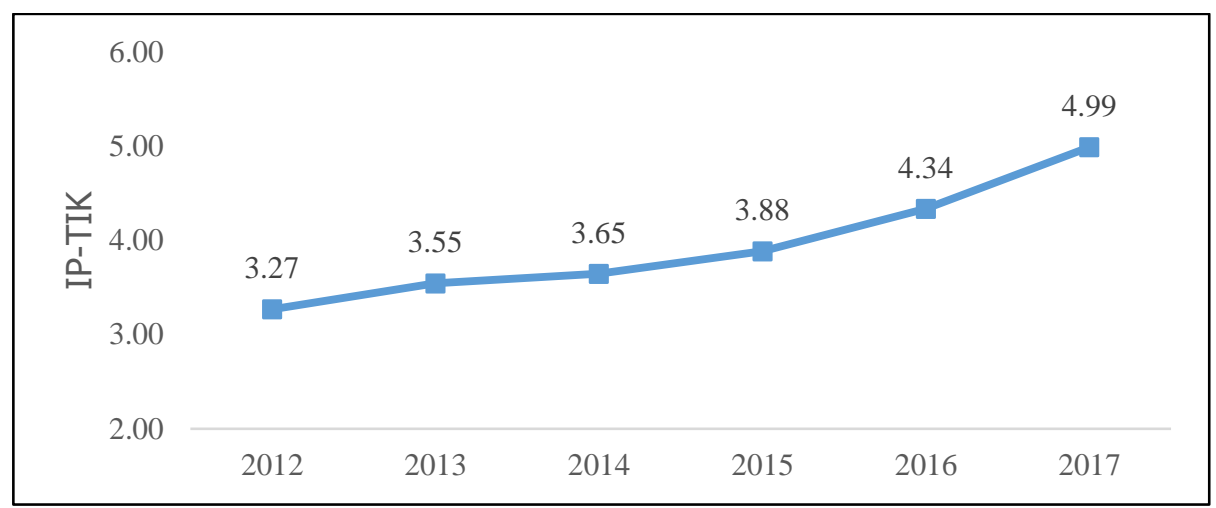

Sumber: Badan Pusat Statistik

Gambar 2. Perkembangan IP-TIK Indonesia tahun 2012-2017

Perkembangan teknologi informasi dan komunikasi di suatu wilayah dapat dilihat melalui Indeks Pembangunan Teknologi Informasi dan Komunikasi (IP-TIK). Semakin tinggi nilai IP-TIK menunjukkan pembangunan TIK di wilayah tersebut semakin baik. Perkembangan IP-TIK Indonesia mengalami perubahan yang pesat, dimana pada tahun 2017 terjadi peningkatan poin sebesar 0,47 poin dari 4,34 di tahun 2016 menjadi 4,99. Perubahan indeks ini menempati rangking 10 besar dunia dalam kategori perubahan nilai IP-TIK (ITU, 2018). Perkembangan Teknologi Informasi dan Komunikasi yang terus meningkat tiap tahun merupakan potensi yang seharusnya dapat dioptimalkan oleh pemerintah untuk menanggulangi kemiskinan.

Karena adanya otonomi daerah, setiap provinsi memiliki kebijakan sendiri dalam mengelola pembangunan di wilayahnya. Selain itu, Teknologi Informasi dan Komunikasi tidak dapat berdiri sendiri, diperlukan infrastruktur lain yang akan menunjang aktivitas perekonomian. Todaro dan Smith (2011) mendefinisikan bahwa investasi kapital berupa jalan raya, transportasi laut dan udara, elektrifikasi, dan layanan publik merupakan faktor penting dalam pembangunan ekonomi. Infrastruktur terdiri dari dua macam, infrastruktur dasar dan infrastuktur pelengkap. Infrastruktur dasar dengan karakteristik digunakan untuk kepentingan publik seperti jalan raya, dan transportasi. Infrastruktur pelengkap meliputi gas, listrik, telepon, dan suplai energi lainnya.

Selain penggunaan teknologi informasi dan komunikasi serta pembangunan infrastruktur, adanya pertumbuhan ekonomi juga mendukung pengentasan kemiskinan. Menurut Todaro dan Smith (2011), salah satu faktor yang dapat mengurangi kemiskinan adalah pertumbuhan ekonomi secara agregat. Pertumbuhan ekonomi yang tinggi dan berkelanjutan merupakan tujuan utama dari pembangunan ekonomi di setiap daerah. Pembangunan ekonomi adalah peningkatan pertumbuhan ekonomi yang tidak hanya dilihat dari kenaikan nilai barang dan jasa tetapi harus memberi perubahan bagi masyarakat, salah satunya peningkatan pendapatan dan kemakmuran masyarakat (Sukirno, 2014). PDRB per kapita merupakan alat yang dapat mengukur tingkat pembangunan ekonomi dan kemakmuran masyarakat.

Berdasarkan pemaparan tersebut, keterkaitan teknologi informasi dan komunikasi, infrastruktur dan pertumbuhan ekonomi sebagai alat yang efektif untuk pengentasan kemiskinan di Indonesia menjadi penting untuk diteliti, maka penelitian ini bertujuan untuk (1) memberikan gambaran umum mengenai tingkat kemiskinan, IP-TIK, dan variabel lain yang terkait, (2) serta untuk menganalisis pengaruh dari IP-TIK, PDRB per kapita, infrastruktur jalan, dan infrastruktur listrik yang diduga memiliki pengaruh terhadap tingkat kemiskinan di Indonesia tahun 2012-2017.

\section{METODE}

Data yang digunakan dalam penelitian ini merupakan data sekunder dari 34 provinsi di Indonesia yang berasal dari Badan Pusat Statistik dengan periode tahun 2012-2017. Terdapat satu provinsi yang memiliki data tidak lengkap yaitu Kalimantan Utara karena merupakan pemekaran daerah sehingga data baru tersedia mulai tahun 2015.

Variabel terikat dalam penelitian ini adalah tingkat kemiskinan yang menggambarkan kondisi kemiskinan di Indonesia, sedangkan variabel-variabel bebas yang digunakan adalah PDRB per 
kapita, IP-TIK, rasio kualitas jalan, dan jumlah listrik yang didistribusikan. PDRB perkapita digunakan sebagai indikator untuk menggambarkan pertumbuhan ekonomi, kemudian untuk menggambarkan ketersediaan infrastruktur menggunakan variabel rasio kualitas jalan, dan jumlah listrik yang didistribusikan. Indeks Pembangunan Teknlogi Informasi dan Komunikasi (IP-TIK) digunakan untuk menggambarkan keberadaan teknologi informasi dan komunikasi. IP-TIK merupakan suatu ukuran standar pembangunan teknologi informasi dan komunikasi suatu wilayah. IP-TIK dapat mengukur pertumbuhan pembangunan TIK, kesenjangan digital antarwilayah, dan potensi pembangunan TIK. Penghitungan indeks komposit IP-TIK menggunakan metodologi yang telah dirumuskan oleh ITU yang telah terbagi dalam tiga subindeks yaitu subindeks akses dan infrastruktur, subindeks penggunaan, dan subindeks keahlian (BPS, 2018).

Analisis yang digunakan dalam penelitian ini menggunakan metode analisis deskriptif dan analisis inferensia. Analisis deskriptif dilakukan dengan menampilkan grafik sedangkan analisis inferensia menggunakan regresi linier data panel tidak seimbang (unbalanced data panel) dengan unit observasi 34 provinsi dan kurun waktu selama 2012-2017. Unbalanced data panel digunakan karena data Kalimantan Utara baru tersedia mulai tahun 2015.

Model yang digunakan dalam unbalanced data panel adalah sebagai berikut (Baltagi, 2005):

$$
\begin{gathered}
y_{i t}=\alpha+\boldsymbol{X}_{i t}^{\prime} \boldsymbol{\beta}+ \\
u_{i t} \ldots \ldots \ldots \ldots \ldots \ldots \ldots \ldots \\
u_{i t}=\mu_{i}+
\end{gathered}
$$

dengan i : $1,2, \ldots, \mathrm{N}$ (individu); $\mathrm{t}: 1,2, \ldots, \mathrm{T}$ (Periode waktu)

Adapun tahapan-tahapan analisis data panel dalam penelitian ini sebagai berikut :

1. Pemilihan model regresi terbaik dilakukan dengan memilih antara tiga model regresi yang biasa digunakan yaitu Common Effect, Fixed Effect, dan Random Effect. Model persamaan yang dibentuk adalah

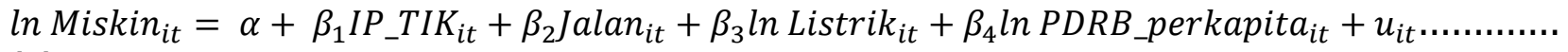

(3)

Keterangan:

Miskin $_{\text {it }}$

IP_TIK

: Tingkat kemiskinan provinsi ke-i tahun $\mathrm{t}$ (persen)

Jalan $_{\text {it }}$ : Indeks Pembangunan Teknologi Informasi dan Komunikasi provinsi ke-i tahun ke-t

Listrik : Rasio kualitas jalan dengan kondisi baik dan sedang per total panjang jalan provinsi ke-i tahun $\mathrm{t}$

PDRB perkapitait : Nilai PDRB per kapita provinsi ke-i tahun $\mathrm{t}$ ( Ribu rupiah)

Penentuan model regresi yang digunakan dilakukan melalui beberapa uji seperti uji Chow, uji Hausman, dan uji BP-LM. Uji Chow dilakukan untuk memilih antara common effect dan fixed effect. Uji Hausman dilakukan untuk memilih antara random effect dan fixed effect. Uji BP-LM untuk memilih antara model CEM dan REM.

2. Menentukan metode estimasi yang digunakan. Model CEM menggunakan metode estimasi Ordinary Least Square sedangkan model REM menggunakan metode estimasi Generalized Least Square. Metode estimasi yang digunakan pada FEM ditentukan setelah melakukan pemeriksaan asumsi matriks varians kovarians.

3. Melakukan pengujian asumsi klasik.

4. Melakukan pengujian keberartian model melalui koefisien determinasi, uji simultan dan uji parsial.

5. Langkah terakhir adalah melakukan interpretasi dari persamaan yang terbentuk. 


\section{HASIL DAN PEMBAHASAN}

Salah satu tujuan utama program Millenium Development Goals dan Sustainable Development Goals adalah pengentasan kemiskinan di seluruh dunia, tidak terkecuali Indonesia. Sejak era reformasi hingga tahun 2017 kemiskinan di Indonesia menunjukkan tren yang menurun setelah mencapai puncak kemiskinan di tahun 1998 akibat adanya krisis ekonomi.

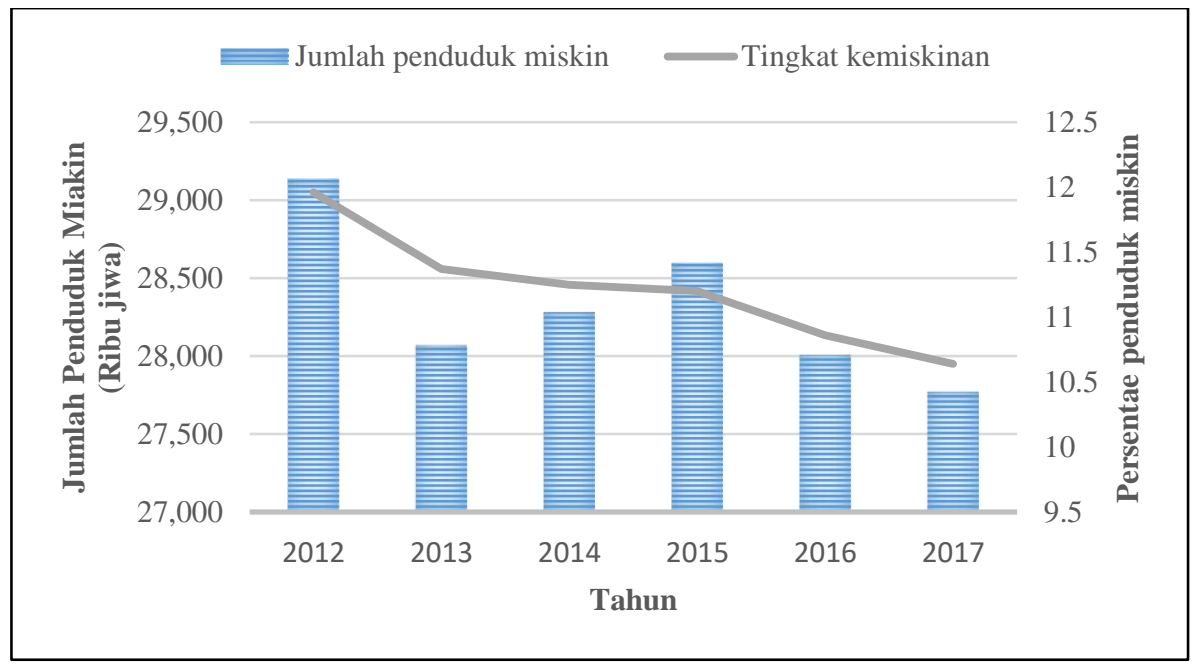

Sumber: Badan Pusat Statistik

Gambar 2. Jumlah penduduk miskin dan tingkat kemiskinan Indonesia tahun 2012 - 2017

Tingkat kemiskinan menunjukkan nilai terendah di tahun 2017 yaitu 10,64 persen. Meskipun tren kemiskinan menurun, tetapi target pengentasan kemiskinan nasional MDGs dan RPJMN 20092014 belum tercapai yaitu menurunkan tingkat kemiskinan hingga dibawah 10 persen. Selama ini pemerintah fokus menerapkan program pengentasan kemiskinan berupa bantuan sosial seperti subsidi dan jaminan sosial. Berbagai program yang diterapkan belum cukup efektif untuk mencapai target pengentasan kemiskinan sehingga perlu dilakukan strategi baru untuk mempercepat pengentasan kemiskinan, salah satunya melalui teknologi informasi dan komunikasi.

Perkembangan Teknologi Informasi dan Komunikasi dapat diketahui melalui Indeks Pembangunan TIK (IP-TIK). Indonesia merupakan salah satu negara dengan perkembangan IP-TIK yang pesat. Di tahun 2017, Indonesia masuk dalam 10 besar negara dengan peningkatan IP-TIK terbesar yaitu sebanyak 0,47 poin dari 4,34 menjadi 4,99 poin. Pesatnya perkembangan IP-TIK didukung oleh peningkatan masing-masing subindeks penyusun IP-TIK. Terdapat tiga subindeks dalam penyusunan IP-TIK yaitu subindeks akses dan infrastruktur, penggunaan, dan keahlian.

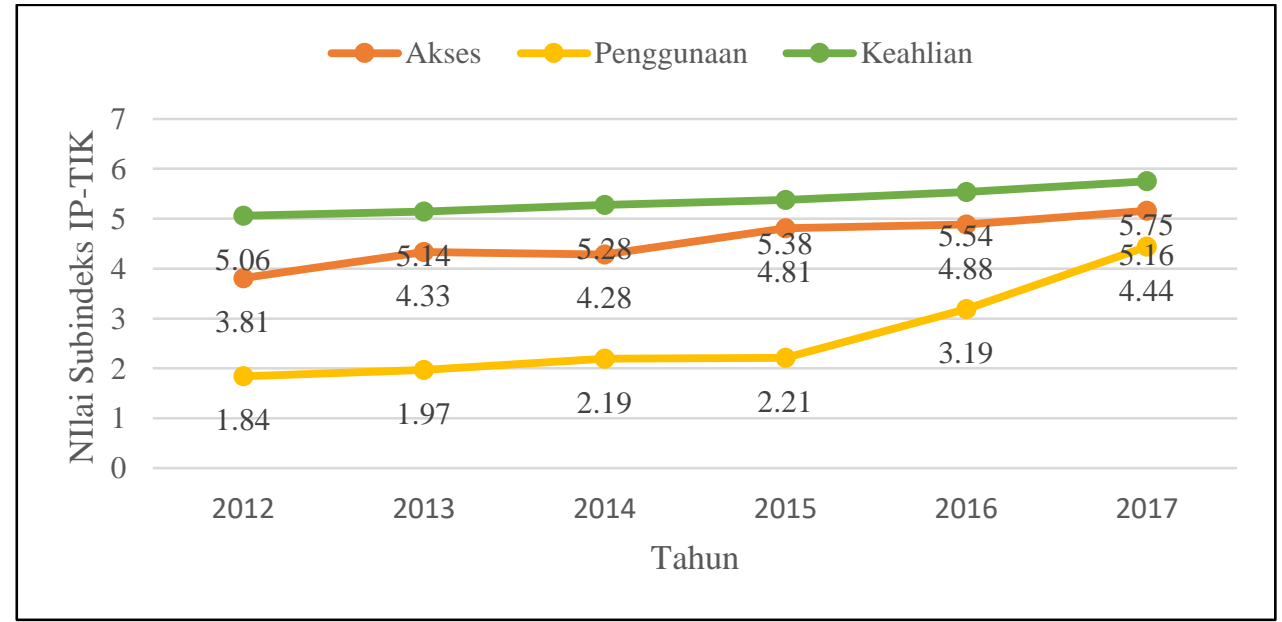

Sumber: Badan Pusat Statistik

Gambar 3. Perkembangan subindeks IP-TIK tahun 2012-2017 
Ketiga subindeks penyusun IP-TIK mengalami peningkatan dari tahun 2012-2017. Dari ketiga subindeks tersebut, peningkatan terbesar terdapat pada subindeks penggunaan. Hal ini dikarenakan penetrasi internet di Indonesia yang berkembang dengan pesat, yaitu dari 21,98 persen di tahun 2015 menjadi 32,34 persen di tahun 2017 (BPS, 2017a). Selain penetrasi internet, jumlah pengguna telepon seluler juga mengalami peningkatan, dimana pada tahun 2015 jumlah penduduk yang memiliki telepon seluler sebanyak 56,92 persen lalu meningkat menjadi 58,30 persen pada 2016 dan di tahun 2017 menjadi sebesar 71,99 persen.

Meskipun secara nasional IP-TIK Indonesia mengalami peningkatan, tetapi masih terjadi masalah pembangunan TIK antarwilayah Indonesia. Provinsi dengan IP-TIK tertinggi adalah DKI Jakarta sebesar 7,61, sedangkan provinsi dengan IP-TIK terendah adalah Papua yaitu sebesar 2,95 (BPS, 2018). Hal ini dikarenakan adanya keterbatasan ketersediaan akses dan kapasitas masyarakat untuk menggunakan teknologi informasi dan komunikasi. Keterbatasan penggunaan teknologi digital ini disebut oleh Barrantes (2007) sebagai digital poverty.

Barrantes membuat empat kategori digital poverty berdasarkan jenis TIK yang digunakan dan memuat beberapa aspek yaitu konektivitas, komunikasi, dan informasi. Pembagian kategori digital poverty yaitu: 1) Extremely Digitally Poor, penggunaan TIK hanya untuk menerima informasi yang bersifat satu arah seperti TV dan radio serta yang tidak memiliki akses TIK; 2) Digitally Poor, terdapat akses informasi dua arah tetapi hanya sebatas untuk menerima informasi dan berkomunikasi seperti telepon seluler dan belum tersedia akses internet; 3) Connected, tersedia akses internet namun penggunaannya bersifat pasif untuk menerima informasi dan komunikasi; 4) Digitally Wealthy, memiliki kemampuan dan akses internet secara aktif dan memanfaatkan berbagai layanan digital.

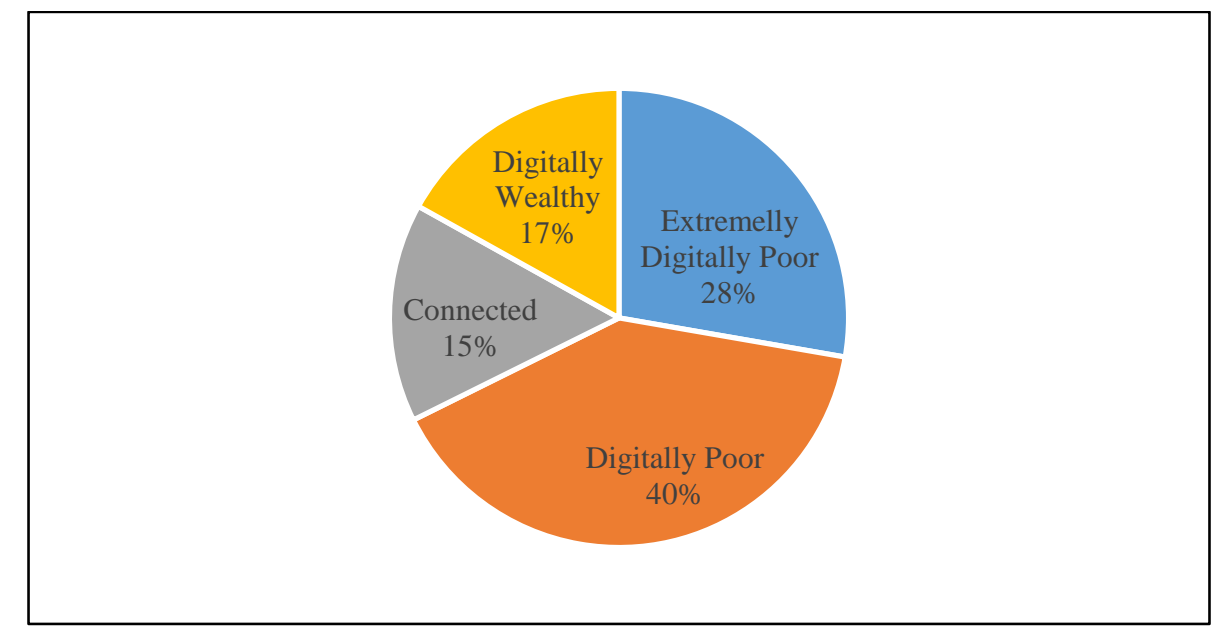

Sumber: Survey Sosial Ekonomi Nasional 2017 (diolah)

Gambar 4. Kategori digital poverty Indonesia tahun 2017

Berdasarkan pengolahan data Susenas 2017, sebagian besar masyarakat Indonesia termasuk dalam kategori Digitally Poor dan Extremely Digitally Poor. Hal ini menunjukkan bahwa teknologi informasi dan komunikasi yang masih dominan digunakan oleh masyarakat merupakan teknologi tradisional seperti Televisi, Radio, dan telepon seluler tanpa akses internet. Meskipun masih didominasi oleh teknologi yang tradisional, tren kelompok Digitally Poor terus mengalami penurunan persentase dari tahun ke tahun, dan sebaliknya tren kelompok Digital Wealthy mengalami peningkatan. (Susanto, 2016). Perlu adanya perhatian pemerintah untuk memperkenalkan dan meningkatkan akses digital pada masyarakat agar pemanfaatan TIK dapat lebih optimal mengingat kemampuan TIK sebagai alat yang efektif untuk mengentaskan kemiskinan. Selain adopsi TIK, untuk mengoptimalkan manfaat TIK dalam pengentasan kemiskinan perlu didukung adanya infrastruktur yang memadai.

Infrastruktur perhubungan darat diperlukan sebagai perantara dalam konektivitas antardaerah di Indonesia. Adanya infrastruktur perhubungan yang baik akan meningkatkan efisiensi dalam kegiatan ekonomi. 


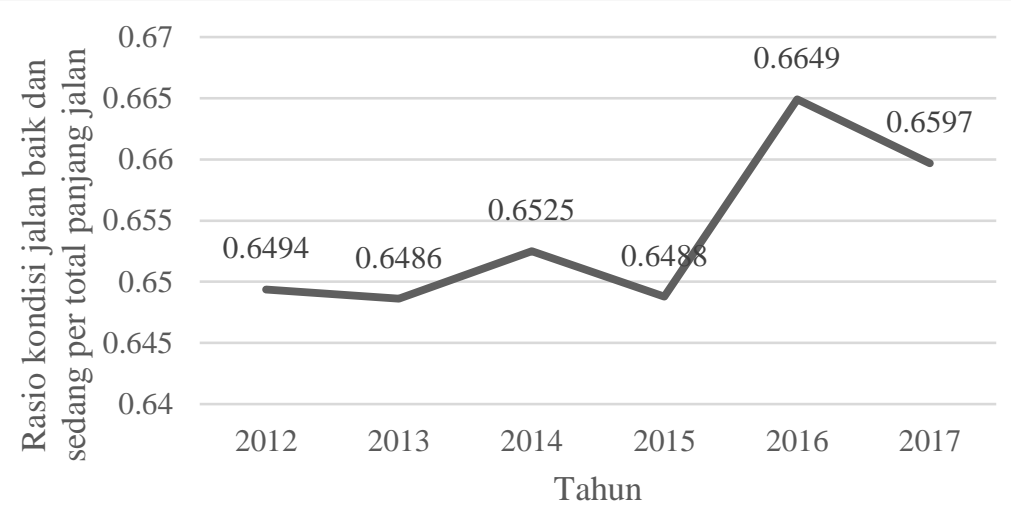

Sumber: Publikasi Statistik Transportasi Darat

Gambar 5. Perkembangan rasio kualitas jalan tahun 2012-2017

Salah satu indikator ketersediaan infrastruktur perhubungan adalah data rasio kualitas jalan baik dan sedang per total panjang jalan. Indikator ini menunjukkan seberapa baik pembangunan dan pemeliharaan infrastruktur jalan oleh pemerintah. Secara umum, kondisi jalan baik dan sedang di Indonesia berada di sekitar nilai 0,65. Nilai ini menunjukkan bahwa dari ketersediaan jalan di Indonesia, jalan dengan kondisi baik dan sedang hanya sekitar 65 persen dan sisanya merupakan kondisi jalan rusak dan rusak berat. Pembangunan infrastruktur jalan merupakan prioritas utama pemerintah untuk mengoneksikan antardaerah dan mempercepat pertumbuhan ekonomi, tetapi pembangunan jalan tidak diiringi dengan pemeliharaan jalan sehingga masih banyak jalan dengan kondisi rusak.

Selain infrastrukur jalan, listrik juga merupakan salah satu kebutuhan pokok yang harus terpenuhi karena setiap aktivitas tergantung pada daya listrik. Sumber energi listrik saat ini masih didominasi oleh sektor batu bara, gas, dan minyak bumi, baik yang dimiliki PLN maupun swasta. Tingginya permintaan akan energi listrik menyebabkan jumlah listrik yang disalurkan terus meningkat tiap tahun. Berdasarkan gambar 6, jumlah listrik yang didistribusikan terus mengalami peningkatan tiap tahun. Energi listrik didistribusikan baik bagi kelompok rumah tangga maupun non rumah tangga. Kelompok rumah tangga merupakan pelanggan listrik terbesar yakni mencapai 92,63\% dari total pelanggan diikuti kelompok komersial dan pelanggan industri. Besarnya konsumsi listrik kelompok rumah tangga juga merupakan yang terbesar dibanding kelompok lain yaitu mencapai 42,04\% dari total listrik yang didistribusikan kemudian diikuti oleh kelompok industri dan kelompok lainnya (BPS, 2017b)

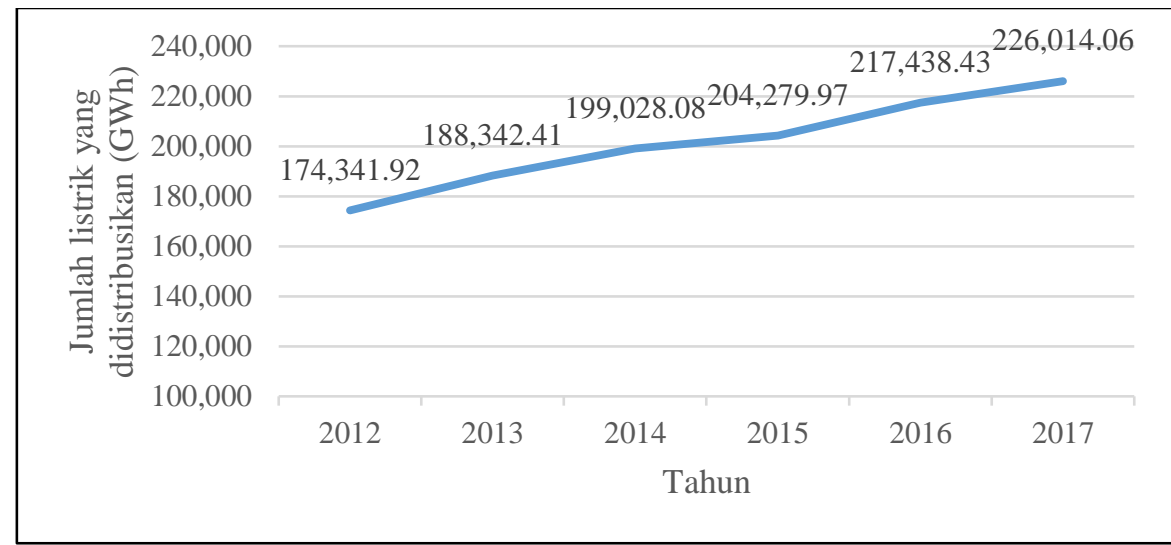

Sumber: Publikasi Statistik Listrik Indonesia tahun 2012-2017

Gambar 6. Perkembangan jumlah listrik yang didistribusikan tahun 2012-2017

Keberhasilan pembangunan dalam suatu wilayah dapat tercermin dari PDRB yang dihasilkan wilayah tersebut. PDRB per kapita menggambarkan nilai barang dan jasa yang dihasilkan oleh suatu wilayah. Keberhasilan pembangunan juga diukur dari keberhasilan suatu wilayah untuk 
mendistribusikan pendapatan secara merata dan adil. Secara umum, PDB per kapita Indonesia menunjukkan nilai yang meningkat dari tahun 2012-2017. Hal ini menunjukkan adanya peningkatan kemakmuran dan kesejahteraan masyarakat.

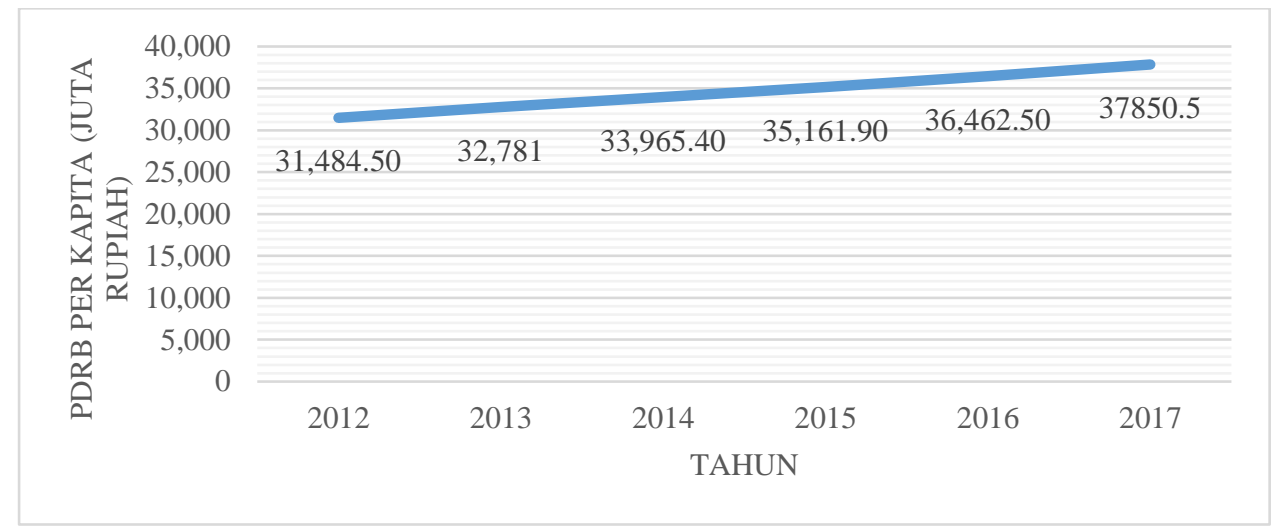

Sumber: Badan Pusat Statistik

Gambar 7. Perkembangan PDB per kapita Indonesia tahun 2012-2017

Selanjutnya untuk mengetahui pengaruh variabel-variabel bebas yang digunakan terhadap tingkat kemiskinan, dilakukan analisis dengan menggunakan analisis regresi data panel untuk menjawab tujuan penelitian yaitu tentang pengaruh IP-TIK, infrastruktur, dan PDRB perkapita terhadap kemiskinan yang dikaji pada masing-masing provinsi di Indonesia. Setelah melakukan beberapa pengujian untuk menentukan model yang terbaik, dengan menggunakan tingkat signifikansi $(\alpha) 5$ persen didapatkan bahwa model regresi terbaik adalah random effect model.

Tabel 2. Hasil Pemilihan Model Terbaik.

\begin{tabular}{cccc}
\hline Statistik Uji & Probability & Keputusan & Kesimpulan \\
\hline Uji Chow & $2,2 \times 10^{-16}$ & Tolak H0 & FEM \\
Uji Hausman & 0,7644 & Gagal tolak HO & REM \\
\hline
\end{tabular}

Setelah terpilih model terbaik yaitu random effect, selanjutnya dilakukan pengujian asumsi klasik untuk mengevaluasi hasil estimasi yang telah diperoleh. Model random effect menggunakan metode estimasi Generalized Least Square sehingga masalah heteroskedastisitas dan autokorelasi telah diatasi dengan metode tersebut. Pengujian asumsi klasik yang diperlukan adalah uji normalitas dan nonmultikolinearitas.

Tabel 3. Hasil uji normalitas.

$$
\text { Jarque Berra test }
$$$$
3,9053
$$

Probabilitas

0,1419
Kesimpulan

Normal

Hasil uji Jarque Berra menunjukkan bahwa tidak terdapat pelanggaran asumsi normalitas dalam model yang terpilih karena $p$-value lebih besar dari tingkat signifikansi yang digunakan. Kemudian dilakukan pengujian untuk menguji asumsi nonmultikolinearitas, yaitu dengan melihat nilai VIF masing-masing variabel. 
Tabel 4. Hasil uji nonmultikolinearitas.

\begin{tabular}{cc} 
Variabel & VIF \\
\hline IP-TIK & 2,63 \\
Jalan & 2,23 \\
Ln (Listrik) & 2,10 \\
Ln (PDRB per kapita) & 1,77
\end{tabular}

Pengujian asumsi normalitas melalui nilai VIF menunjukkan bahwa model terpilih telah memenuhi asumsi nonmultikolinearitas karena semua variabel memiliki nilai VIF kurang dari sepuluh.Berdasarkan hasil pengujian asumsi klasik, model yang terpilih tidak melanggar asumsi klasik yang diperlukan.

Selanjutnya untuk membentuk model estimasi pengaruh IP TIK, infrastruktur jalan dan listrik, serta PDRB per kapita terhadap kemiskinan di Indonesia dengan menggunakan metode estimasi Generalized Least Square dan metode estimasi varians Swamy-Arora secara ringkas dapat ditulis sebagai berikut :

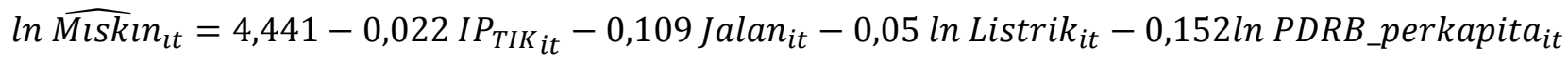

Hasil dari estimasi model terbaik menunjukkan bahwa uji simultan dengan statistik uji Wald $\chi 2$ signifikan pada tingkat signifikansi 5 persen, yang menunjukkan bahwa variabel-variabel bebas yang digunakan pada persamaan regresi data panel secara simultan (bersama-sama) signifikan dalam memengaruhi tingkat kemiskinan di Indonesia. Nilai Adjusted $\mathrm{R}^{2}$ dari hasil pengolahan data adalah 0,30209 yang menunjukkan bahwa besarnya proporsi variasi dari variabel tingkat kemiskinan yang bisa dijelaskan oleh variabel bebas pada model tersebut sebesar 30,21 persen, sedangkan sisanya sebesar 69,79 persen dijelaskan oleh variabel lain di luar model. Meskipun hasil pengolahan menunjukkan nilai $R^{2}$ yang kecil tidak berarti bahwa model yang dihasilkan buruk (Gujarati, 2009). Hal ini menunjukkan bahwa infrastruktur, pertumbuhan ekonomi dan TIK tidak dapat berdiri sendiri untuk mengentaskan kemiskinan, variabel ini sebagai penunjang agar program-program pengentasan kemiskinan yang dilakukan pemerintah berjalan lebih efektif. Santoso dalam Widiyastuti (2015) menjelaskan bahwa ada tiga hal penting agar TIK efektif sebagai alat pengentasan kemiskinan,yaitu 1) TIK adalah kondisi yang dibutuhkan tetapi juga tidak lengkap; 2) TIK menjadi bagian yang tidak lepas dari program pengentasan kemiskinan; 3) Implementasi program TIK dan pengentasan kemiskinan harus terintegrasi dan terpadu.

Berdasarkan hasil penelitian, keempat variabel bebas memiliki hubungan negatif dan signifikan terhadap tingkat kemiskinan. Kenaikan satu poin Indeks Pembangunan Teknologi Informasi dan Komunikasi maka laju tingkat kemiskinan akan turun 0,022 persen dengan asumsi variabel lain konstan. Seperti yang dikemukakan oleh Widiastuti (2010), melalui pemerataan teknologi informasi dan komunikasi di bidang ekonomi, peluang lapangan usaha akan lebih banyak tersedia sehingga akan meningkatkan kesejahteraan masyarakat.

Salah satu pemanfaatan TIK adalah dalam bidang pertanian dimana mayoritas masyarakat miskin bekerja di bidang ini, TIK berfungsi sebagai media yang menyimpan informasi tentang pertanian dan media komunikasi yang mendukung kegiatan penyuluhan pertanian sekaligus menyediakan akses pemasaran pertanian yang lebih luas sehingga mampu meningkatkan kesejahteraan petani. TIK menyediakan informasi mengenai kondisi cuaca, harga pupuk, diseminasi, dan teknologi yang berkaitan dengan pertanian (Kominfo, 2015). Perkembangan TIK juga mengubah struktur pelayanan jasa pemerintah. Sesuai dengan analisis Cecchini (2003) bahwa TIK memberikan kesempatan pada orang miskin untuk memanfaatkan jasa pelayanan pemerintah dengan lebih efektif. Selain menyediakan jasa pelayanan masyarakat, TIK dapat digunakan sebagai ajang promosi potensi desa, seperti memasarkan hasil pertanian, promosi lokasi wisata, dan hasil kerajinan produk dari usaha kecil dan menengah (Praditya, 2014). Sektor UMKM memiliki kontribusi yang tinggi pada perekonomian Indonesia. Adanya TIK memungkinkan bagi pelaku UMKM untuk memperluas pasar baik pasar domestik hingga pasar internasional 


\section{KESIMPULAN}

Dari hasil regresi pengaruh Indeks pembangunan teknologi informasi dan komunikasi, PDRB per kapita, rasio kualitas jalan, dan jumlah listrik yang didistribusikan terhadap tingkat kemiskinan di Indonesia tahun 2012-2017 dapat disimpulkan bahwa semua variabel bebas memiliki hubungan negatif dan signifikan pada tingkat signifikansi 5 persen terhadap tingkat kemiskinan.

Dari hasil penelitian, didapat bahwa Indeks pembangunan teknologi informasi dan komunikasi berpengaruh terhadap tingkat kemiskinan, sehingga perlu adanya peningkatan baik dari segi infrastruktur fisik telekomunikasi maupun penggunaan TIK serta dilakukan upaya penyuluhan maupun literasi bagi masyarakat miskin agar mau dan mampu memanfaatkan TIK sehingga dapat meningkatkan produktivitas masyarakat.

\section{DAFTAR PUSTAKA}

Badan Pusat Statistik. (2017a). Statistik Kesejahteraan Rakyat 2017. Jakarta: BPS. . (2017b). Statistik Listrik 2012-2017. Jakarta : BPS.

(2018). Indeks Pembangunan Teknologi Informasi dan Komunikasi. Jakarta:BPS.

Baltagi, Badi H. (2005). Econometric 3th edition. Wst Sussex: John Wiley \& Sons.

Bappenas dan UNDP. (2008). Teknologi Informasi dan Komunikasi: Strategi Peduli Kemiskinan. Jakarta: Bappenas.

Barrantes, R. (2007). Analysis of ICT Demand: What Is Digital Poverty and How to Measure It? In I. D. R. Centre. (Ed.). Practical Action Publishing.

Cecchini, Simon. (2003). Tapping ICT to Reduce Poverty in Rural India. IEEE Technology and Society Magazine, Summer 2003.

Gujarati, Damodar N., dan Porter, Dawn C (2009). Basic Econometrics. Fifth Edition. New York: The McGrow Hill Companies Inc.

International Telecommunication Union. (2018). Measuring the Information Society Report 2016. Geneva: ITU.

Kementerian Komunikasi dan Informatika. (2015). Pemanfaatan dan Pemberdayaan Teknologi Informasi dan Komunikasi pada Petani dan Nelayan (Survey Rumah Tangga dan Best Practices). Jakarta : Kementerian Komunikasi dan Informatika.

Praditya, Didit. (2014). Pemanfaatan Teknologi Informasi dan Komunikasi di Tingkat Pemerintahan Desa. Jurnal Penelitian Komunikai Vol 17 No 2 Desember 2014: 129-140.

Sukirno, Sadono. (2014). Ekonomi Pembangunan Proses, Masalah, dan Dasar Kebijakan. Edisi Kedua. Jakarta: Kencana, Prenada Media.

Susanto, Anton. (2016). Analisis Kondisi Digital Poverty di Indonesia. Jurnal Penelitian Pos dan Informatika JPPI Vol 6 No 2 169-184

Todaro, Michael P. dan Smith, Stephen C. (2011). Pembangunan Ekonomi. Edisi Kesebelas. Jakarta: Erlangga.

Widiastuti, Tuti. (2010). Kemiskinan Struktural Informasi. Jurnal Ilmu Komunikasi Vol 8, No. 3, September-Desember, 2010: 314-329.

Widiyastuti, Inasari. (2015). Analisis Runtun Waktu dalam Pengujian Pengaruh TIK terhadap Penurunan Laju Kemiskinan di Indonesia. IPTEK-KOM, Vol. 17 No 1: 19-30.

Yusup, Pawit M., Kuswarno, Engkus., dan Kurniasih, Nuning. (2017). Aspek Keterbatasan Informasi Penghidupan Orang Miskin Pedesaan. Jurnal Masyarakat, Kebudayaan dan Politik Vol 30. No 1 tahun 2017: 34-47. 